\title{
Resentimiento y Apocalipsis. La critica de Nietzsche a las visiones del fin de los tiempos ${ }^{1}$ \\ VOLKER GERHARDT \\ Universidad de Münster
}

Alguien que quisiera ocuparse de la serie de declaraciones relativas al tema del Apocalipsis, puede afirmar que Friedrich Nietzsche no pertenece al contexto de este tema. Nietzsche menciona el Apocalipsis, ya sea en sentido teleológico o en sentido histórico, en tan contadas ocasiones, que el concepto ni siquiera se encuentra en el registro de Richard Oehler ${ }^{2}$. Karl Schlechta señala en los escritos publicados por el propio Nietzsche un único pasaje en el que se trata el Apocalipsis según san Juan ${ }^{3}$. El diagnóstico tampoco se modifica si se consultan sus fragmentos póstumos o sus cartas. El Apocalipsis no es un tema para Nietzsche. La tradición del Nuevo Testamento es traída a colación por él de forma tan escueta como la visión, constantemente reactualizada por aquella tradición, de un catastrófico juicio universal, por el cual todos, excepto la pequeña multitud de los justos, finalmente serán condenados.

Con esta constatación podría cerrar mi exposición. Si quisiera ajustarme en sentido estricto al procedimiento de aquellos que desean leer a Nietzsche e interpretarlo al pie de la letra, no me quedaría, pues, sino citar simplemente el mencionado pasaje y dejar todo lo demás en suspenso. Pero semejante

${ }^{1}$ Hemos de agradecer al profesor Manuel Barrios Casares, de la Universidad de Sevilla, no sólo el que despertara hace años nuestro interés específico por los estudios nietzscheanos y nos orientara al conocimiento de la obra del profesor Gerhardt, sino también sus oportunas observaciones en la lectura y revisión de esta traducción. Así mismo, queremos mostrar nuestra gratitud al profesor Volver Gerhardt por la cálida acogida dispensada a este proyecto (Nota del traductor).

${ }^{2}$ Oehler, R., Nietzsche-Register. Alphabetisch-systematische Übersicht über Friedrich Nietzsches Gedankenwelt nach Begriffen und Nammen, Stuttgart, ${ }^{4} 1970$ (1943).

${ }^{3}$ Schlechta, K., Nietzsche-Index, München: Hanser, 1965, en SA. 
actitud, ostensivamente irreflexiva, no hace justicia a la fecundidad de ideas demostrada por Nietzsche. No podemos tratarlo como mero texto. Por tanto, debemos prestar atención a lo que dicha formulación significa para Nietzsche y, ante todo, lo que esto supone para nosotros. Así pues, partimos del convencimiento de que no practicamos ningún agravio contra Nietzsche si lo tomamos en serio como filósofo. Con seguridad él es más que un filósofo en sentido académico. Después de la división de trabajo establecida por la cultura moderna, debemos admirar también en él al filólogo, al psicólogo y al artista. Sin embargo, y por encima de todo su virtuosismo filológico, psicológico, literario y musical, Nietzsche sigue siendo un pensador conceptual analítico y constructivo, en quien, incluso, cabe reconocer estimables esfuerzos sistemáticos. Además, no existe duda alguna de que él se comprendió a sí mismo como un filósofót. Pues, como 'librepensador', que es lo que deseaba ser por encima de toda etiqueta, se incluyó una y otra vez a sí mismo expresamente entre los filósofos.

De ahí que me tome la libertad de reprensarlo como filósofo. En consecuencia, puedo exponerlo con medios conceptuales y atribuirle un pensamiento, expresado con suficiente clarividencia en aquel pasaje en el que se menciona el Apocalipsis. Sólo poseemos, por tanto, desde el punto de vista filológico, una base muy exigua (tomado al pie de la letra: solamente un único pasaje); pero quizás se descubra este como suficiente a la hora de recrearnos una idea que nos permita intuir qué es lo que piensa Nietzsche acerca del Apocalipsis. Posiblemente, incluso, nos permita aventurar una tesis que explique por qué lo trata en tan contadas ocasiones.

El pasaje aludido se encuentra en el penúltimo párrafo del primer tratado de La genealogía de la moral. Este primer tratado figura con el lapidario título: «Bueno y Malvado’, 'Bueno y Malo’». Sobre él vuelve explícitamente Nietzsche al final de sus reflexiones:

«Concluyamos. Los dos valores contrapuestos 'bueno y malo', ,bueno y malvado' han sostenido en la tierra una lucha terrible, que ha durado milenios; y aunque es muy cierto que el segundo valor hace mucho tiempo que ha prevalecido, no faltan, sin embargo, tampoco ahora lugares en los que se continúa librando esa lucha, no decidida aún. Incluso podría decirse que entre tanto la lucha ha sido llevada cada vez más arriba y que, precisamente por ello, se ha vuelto cada vez más profunda, cada vez más espiritual: de modo que hoy quizás no exista indicio más decisivo de la 'naturaleza superior'

${ }^{4}$ Consultar del propio autor, Friedrich Nietzsche, München, 1992, y «ExperimentalPhilosophie», en Pathos und Distanz, Stuttgart, 1989. 
que estar escindido en aquel sentido y que ser realmente todavía un lugar de batalla de aquellas antítesis» ${ }^{5}$.

Aquí no se halla todavía la expresión buscada. Pero el pasaje es digno de ser reseñado, porque en él Nietzsche explica el desarrollo de la cultura humana a partir de la continua lucha entre la virtud individual y la moral abstracta, lucha desplegada de manera cada vez más sutil en el transcurso de los siglos ${ }^{6}$. Asimismo, en dicho pasaje descubrimos también aquello que Nietzsche concibe propiamente bajo el concepto de 'profundidad', tan empleado por él, y a menudo cargado con connotaciones misteriosas; a saber, nada mas que lo espiritual mismo. Deduciéndose, en fin, cómo lo espiritual nace, pues, en esa lucha entre valoración individual y colectiva.

Esta observación incidental puede ser valorada como un simple indicio de que Nietzsche, quien de forma tan aguda juzgó la moral abstracta, ha procurado, al mismo tiempo y no obstante, concederle justicia histórica. La moral del esclavo incluso puede ser mendaz y reprobable: pero aun así toma parte en la espiritualidad de la cultura humana. Por consiguiente, no es irrelevante para su consiguiente desarrollo fijar la vista en el reconocimiento de los méritos históricos de la fe judía y cristiana.

En continuidad con las citadas frases prosigue Nietzsche: «El símbolo de esa lucha, escrito en caracteres que han permanecido hasta ahora legibles a lo largo de la historia entera de la humanidad, dice "Roma contra Judea, Judea contra Roma”: - hasta ahora no ha habido acontecimiento más grande que esta lucha, que este planteamiento del problema, que esta contradicción de enemigos mortales. Roma veía en el judío algo así como la antinaturaleza misma, como su monstrum antipódico, si cabe la expresión; en Roma se consideraba al judío 'convicto de odio contra todo el género humano': con razón, en la medida en que hay derecho a vincular la salvación y el futuro del género humano al dominio incondicional de los valores aristocráticos, de los valores romanos» ${ }^{7}$.

Aquí, por consiguiente, se concreta históricamente la antítesis entre la virtud individual-aristocrática y la moral abstracta-general. La primera se encarna en el monumental ideal de dominación del mundo romano, que también acoge en sí la herencia de la antigüedad griega. La segunda se perfila en el judaísmo, y podemos concluir ya, partiendo de la primera constatación

${ }^{5}$ GM I $\$ 16$, KSA V 285s. [N. del t.: las citas de obras de Nietzsche en castellano siguen las publicadas en Alianza Editorial por Andrés Sánchez Pascual].

${ }^{6}$ Consultar del propio autor, Genealogische Ethik. Nietzsches Moral der Individualität, en Pieper, A., (ed), Grundzüge der Ethik, Stuttgart/Bern, 1992.

${ }^{7}$ Ibid. 
hecha, que la lucha entre Roma y Judea aún hoy en día no se encuentra decidida. Por eso, no se trata simplemente de poseer conocimientos de interés histórico acerca de cómo los romanos llegaron a vivenciar a los judíos como la encarnación del odio, sino que también tenemos la obligación de saber cómo a su vez valoraron los judíos a los romanos. Pues solamente si también conocemos el juicio de la otra parte podremos estimar la, presuntamente aún actual, -aunque con medios mucho más sutiles- dirimida oposición.

Nietzsche no nos parece responsable de este sesgo de información. Pues de inmediato pregunta qué es lo que los judíos han «sentido contra los romanos», y su impresión es que la respuesta está a mano; al menos, que se puede adivinar 'por mil indicios': «Se lo adivina por mil indicios; pero basta con traer una vez más a la memoria el Apocalipsis de San Juan, la más salvaje de todas las invectivas escritas que la venganza tiene sobre su conciencia» ${ }^{8}$. Aquí tenemos el pasaje anunciado. El Apocalipsis, atribuido al discípulo Juan, es decir el libro de la revelación (Apocalipsis) del Nuevo Testamento, se valora como el documento que sitúa a la sombra a todos los demás indicios del odio judío contra el pueblo romano. La expresión no podría ser más dura. Escúchese: se describe el libro como la «más salvaje [...] de todas las invectivas escritas», que el deseo de venganza creó jamás. El instinto más vil pensable debe se halla en los mecanismos de ese libro, y no se afana con brutalidad directa, sino que se sirve de los medios de engaño más maliciosos. Además, a ojos de Nietzsche, resulta un agravante el que esa invectiva del odio se haya atribuido posteriormente a aquel discípulo tenido en la historia escrituraria como el más tierno:

«Por otro lado, no se infravalore», añade Nietzsche entre paréntesis a propósito de la citada opinión, «la profunda consecuencia lógica del instinto cristiano al escribir cabalmente sobre este libro del odio el nombre del discípulo del amor, del mismo a quién él [el instinto cristiano] atribuyó aquel Evangelio enamorado y entusiasta; - aquí se esconde un poco de verdad, por muy grande que haya sido también la falsificación literaria necesaria para lograr este fin»?.

Esta adición permite reconocer que a Nietzsche no le era desconocido el debate crítico-textual del XIX, orientado en todos sus aspectos en torno a las revelaciones de $\operatorname{san} \operatorname{Juan}^{10}$.

${ }^{8}$ Ibid.

${ }^{9}$ Ibid.

${ }^{10}$ Cf. al respecto, de la época de Nietzsche, Baur, F. C., Kritische Untersuchungen über die kanonischen Evangelien, Tübingen, 1847; Hilgenfeld, A., Das Evangelium und die Briefe 
Por una carta escrita el 10 Octubre de 1866, durante la época de sus estudios en Leipzig, sabemos que ya por aquel entonces Nietzsche se confrontó, junto con sus compañeros de estudios, con el prologo del Evangelio según san Juan, el cual ya fue intenso objeto de comentario en el espíritu de la filosofía antigua ${ }^{11}$. Nietzsche se encontraba además familiarizado, a través de sus lecturas de los escritos de David Friedrich Strauss, con los popularizados estudios de sus contemporáneos sobre la vida de Jesús ${ }^{12}$. Así pues, manejaba la tesis de que el autor del Evangelio según san Juan no era el mismo que el del Apocalipsis.

Una prueba de esto se encuentra en una anotación póstuma de los años 1870/1871. En ella Nietzsche retiene para sí lo siguiente: «El evangelio según san Juan, nacido a partir de una atmósfera griega, a partir de suelo dionisíaco: su influencia sobre el cristianismo, en antítesis a la influencia judía» ${ }^{13}$. Con este apunte también se hacen comprensibles otros dos fragmentos póstumos de la misma época, en los que Nietzsche anotó la división prevista para los tratados que planeaba. Allí se concibe entre otros el propósito de trabajar sobre el «alejandrinismo del conocimiento, procesión hacia la India. La salvaje irrupción de los dionisíaco», y, a continuación, escribir un texto sobre "san Juan» ${ }^{14}$. Poco después, Nietzsche se propone componer un tratado que se ocupe en primer lugar (I) del «nacimiento del pensamiento trágico», después exponga (II) «la tragedia misma», (III) «el ocaso de la tragedia» y, finalmente, (IV) «san Juan» ${ }^{15}$.

No se llega a la realización de estos planes concretos. Sin embargo, no es difícil reconocer aquí los primeros atisbos de la concepción de otro escrito, es decir, de El nacimiento de la tragedia a partir del espiritu de la música, que aparecería más tarde, en 1872. Ahí encontramos las reflexiones sobre la tragedia y lo dionisíaco anunciadas en los proyectos, así como también aparecen sendas versiones sobre el alejandrinismo y la procesión hacia la India. Pero ninguna palabra sobre el Evangelio de san Juan.

Johannis nach ihrem Lehrbegriff, Halle, 1854 y Die jüdische Apokaliptik, Jena, 1857; Thoma, A., Die Genesis des Johannesevangeliums, Berlin, 1882.

${ }^{11}$ KSB VIII 165: Carta a H. Muschacke, 10-10-1886. Según informe de Nietzsche, el compañero de estudios, Wilhelm Wisser, disertó «en la asociación filológica sobre el prólogo de san Juan».

${ }^{12}$ Strauß, D. F., Das Leben Jesu, 2. Bde., Tübingen, 1835, ${ }^{4} 1840$; y Der alte und der neue Glaube, Leipzig 1872 (Nietzsche se enfrentó polemicamente a este libro en la primera de sus Consideraciones intempestivas).

${ }^{13}$ KSA VII 139: 7[13].

${ }^{14}$ KSA VII 134: 6[14].

${ }^{15}$ KSA VII 139: 7[14]. 
Sólo podemos especular sobre qué puente histórico podría haber realizado Nietzsche la conjurada conexión entre la cultura griega y la alemana, caso de haber realizado ese proyecto -, sin duda, hubiese debido someter el evangelio de san Juan a una consideración más detenida. Seguramente eso hubiese arrojado una tenue luz sobre su crítica radical al cristianismo. Lo que más tarde hubo de aflorar de comprensión por el 'hebreo Jesús', habría podido ampliarse también a un libro, al menos, del Nuevo testamento, y le hubiese dado, bajo ciertas circunstancias, razones para excluir el cristianismo primitivo de sus anatemas. Pero Nietzsche no retoma ni una sola vez ni la senda ni la figura del evangelista Juan, y, así, estas consideraciones quedan como meras especulaciones.

En cambio, Nietzsche se manifestó de forma tanto más detallada en sus escritos tardíos acerca del espíritu de venganza que veía operar en los mecanismos del Apocalipsis según san Juan. A ese espíritu de venganza lo denomina 'resentimiento'. Con ello se alude, en sentido literal, un sentimiento reactivo, mediante y gracias al cual alguien intenta rechazar sus propias debilidades. Con el resentimiento, el sentimiento de inferioridad se compensa a través de la desvalorización del superior. El débil se resarce del fuerte.

La distinción entre 'débiles' y 'fuertes' o, por ser más precisos, entre una 'voluntad débil' y una 'voluntad fuerte' pertenece a los elementos básicos de la crítica moral y social en Nietzsche. También está a la base de sus esfuerzos por desarrollar la virtud del espíritu libre y, así, la responsabilidad del 'individuo soberano'. Con todo ello queda puesto de manifiesto que 'fuertes' y 'débiles' no se conciben en el sentido de una relación de fuerzas físicas, sino que se trata de un genuino ejercicio de poder en la unidad autocomprensiva de fuerzas interiores y exteriores. En la 'voluntad fuerte' de un hombre aún siempre se halla la confianza en las propias posibilidades. Por consiguiente, la 'voluntad fuerte' es la fuerza que se abre en esa confianza en sí misma y que se manifiesta de manera directa.

A la 'voluntad débil', por el contrario, le falta esa confianza en las propias capacidades. La limitación de las propias posibilidades que siempre se hallan presentes en la vida las experimenta como fracaso, por el cual, sin embargo, no se culpabiliza a sí misma, como tampoco a la realidad de la naturaleza o de la historia. En vez de eso, estiliza su fracaso como padecimiento en los otros. El motivo de su incapacidad lo ve en su trato con el otro y, naturalmente, puesto que el otro es causa del propio sufrimiento, se lo representa como un caso de prepotencia y de escandalosa injusticia. De esa forma surge la imputación de la culpa a aquellos con los que el débil, en su propio 
sufrimiento, no sabe congeniar. En consecuencia, el débil define a aquéllos como violentos y brutales, pues a través de su supuesta carencia de sensibilidad dan a entender al doliente que no están capacitados para el sufrimiento. Y al margen de que los otros, vivenciados por los débiles como superiores y, puedan ser despreciados como gentes sin espíritu y potentados, se les valora ahora también como moralmente malvados. Y no son simplemente 'malos' porque presuntamente no puedan hacer aquello que ellos estiman como bueno, sino que desde este momento se les representará como profundamente 'malvados'. Así llega al mundo, según Nietzsche, el llamado 'Mal', y éste no se origina sino a partir del sentimiento de venganza, por tanto, a partir del espíritu de resentimiento.

En qué constelación histórica cabe pensar para el surgimiento de este sentimiento es algo que se indica a renglón seguido en este pasaje de GM que citamos: «Los romanos eran, en efecto, los fuertes y los nobles; en tal grado lo eran que hasta ahora no ha habido en la tierra hombres más fuertes y más nobles, y ni siquiera se los ha sońado nunca; toda reliquia de ellos, toda inspiración suya produce éxtasis, presuponiendo que se adivine qué es lo que allí se escribe. Los judíos, en cambio, eran el pueblo sacerdotal del resentimiento por excelencia, en el que habitaba una genialidad popularmoral sin igual»" ${ }^{16}$. Y a eso se conecta la pregunta retórica: «¿Quién de ellos ha vencido entre tanto, Roma o Judea? No hay, desde luego, la más mínima duda: considérese ante quién se inclinan hoy los hombres, en la misma Roma, como ante la síntesis de todos los valores supremos, - y no sólo en Roma, sino casi en media tierra, en todo los lugares en que el hombre se ha vuelto manso o quiere volverse manso. - Ante tres judíos, como es sabido, y una judía (antes Jesús de Nazaret, el pescador Pedro, el tejedor de alfombras Pablo, y la madre del mencionado Jesús, de nombre María). Esto es bastante curioso: sin ninguna duda, Roma ha sucumbido» ${ }^{17}$.

Todavía a finales del siglo XX hay escasos motivos para dudar de ese diagnóstico histórico. No obstante, si nos interesa saber por qué Nietzsche llega a rechazar el Evangelio de san Juan como la forma más llamativa del resentimiento judeo-cristiano, debemos investigar a fin de comprender qué valores vincula él junto con la victoria histórica de lo cristiano sobre la antigua

${ }^{16}$ GM I $\$ 16$, KSA V 286.

${ }^{17}$ GM I $\$ 16$, KSA V 286s. Para una estimación de las expectativas del propio Nietzsche ha de considerarse la siguiente frase, no citada arriba: «Sea como fuere, en el Renacimiento se dio una espléndida e inquietante resurrección del ideal clásico, de aquella manera aristocrática de valorar todas las cosas [...]» GM I \$16, KSA V 287. 
Roma. El intento merece la pena con independencia de nuestro tema, ya que ahí podemos reconocer al mismo tiempo aquello que Nietzsche concibe propiamente bajo el concepto, por él mismo popularizado, de nihilismo. Pues, a fin de cuentas, es justamente el nihilismo aquel que puede hallar una adecuada realización bajo el catastrófico desastre mundial del Apocalipsis.

El juicio de Nietzsche sobre 'Judea' no surge de un prejuicio racista y se posiciona también bastante lejos de ser antisemita. Precisamente hacia el antisemitismo propagado en su época y en su entorno directo no manifestó sino menosprecio ${ }^{18}$. Cuando valora el judaísmo histórico de la época testamentaria se refiere rigurosamente a un tipo de dominio cultural y, más tarde, a un tipo de dominio político que asciende al poder: el tipo del sacerdote asceta. Éste asciende al poder, mientras lo niega; domina el mundo, mientras lo condena. Así mismo transforma el poder y el mundo en entidades tan malas, que éstas se revelan como la maldad por antonomasia, para, en seguida, proponerse a sí mismo como única instancia capaz de superar esa maldad.

La especie del sacerdote asceta se da, según Nietzsche, en muchas culturas. A modo de ejemplo desarrolla más detalladamente en El anticristo por qué el budismo también se encuentra bajo el ideal de negación del mundo ${ }^{19}$. Y partiendo de ahí presupone que la tierra -contemplada desde «una estrella lejana»- debe mostrarse como el «astro auténticamente ascético». Por consiguiente, se dan múltiples formas de ascetismo, pero de ninguna manera pueden considerarse todas como igualmente horrendas y devastadoras.

Pero entre todas ellas existe una que se permite llegar al exceso, que sobrepuja a todo cuanto ha sido hasta ahora, contra la que se dirige el ataque más afilado de Nietzsche. Esa es la dominación del sacerdote judeo-cristiano. Ella conduce hasta la «insurrección de los esclavos en la moral», impone de forma universal su 'moral de rebaño' y amenaza, en su establecida alianza con la ciencia moderna, el futuro de los hombres. De esa forma llegamos con Nietzsche a la paradójica constatación de que, calibrando precisamente el poderosísimo efecto de todas las religiones monoteístas, persistente durante siglos, y de la creencia de los judíos y los cristianos, extendida por todo el mundo, ha germinado el nihilismo moderno.

Desde la compleja argumentación que Nietzsche desarrolla, sobre todo en La genealogía de la moral y en El anticristo, hasta los numerosos fragmentos póstumos que desde el año 1886 hasta 1888 tratan sobre este tema, sólo en

${ }^{18}$ Consultar para ello del mismo autor, Friedrich Nietzsche, pp. 22s.

${ }^{19}$ AC $\$ 23$, KSA VI 186-191. 
unos pocos compases puede hallarse ya alguna alusión de que la tradición del antiguo testamento se basa en una falsificación de la original creencia popular de los israelitas, expresión de la 'autoafirmación' y de la 'conciencia de poder' de un pueblo del desierto. Aún era su Dios Javeh una expresión del 'regocijo de sî́ y de la 'esperanza en sî': «en él se aguardaba la victoria y la salvación, con él se confiaba en que la naturaleza diese lo que el pueblo necesita -ante todo, lluvia ${ }^{20}$. Durante bastante tiempo cumplió ese Dios aquello que de él se esperaba.

Pero entonces, en la época de los reyes, se produjo un declive, en el interior dominaba la 'anarquía', del exterior amenazaba constantemente la superioridad numérica de los asirios. Las esperanzas depositadas en el antiguo Dios ya nunca más se cumplieron. Pero, en aquel momento, en vez abandonarlo, se le retuvo con toda terquedad, cosa que solamente pudo acontecer a través de una serie de cambios en su concepto. Y esto fue obra de los sacerdotes. Y, de ese modo, el concepto de Dios pasó a ser sólo «Un instrumento en manos de agitadores sacerdotales, que, a partir de ese momento, interpretan toda ventura como un premio, toda desventura como un castigo por la desobediencia a Dios, por el 'pecado' $»^{21}$.

Así se llega a la realización del 'prodigio de la falsificación', y como documento suyo se presenta, según considera Nietzsche, el Antiguo Testamento. El mundo es interpretado conforme al hilo conductor de una causalidad contranatura, la naturaleza entera se convierte en 'antinatural' y del Dios que da, que ayuda y seduce a la vida, se llega a un 'Dios que exige'. Bajo su mandato -tras el cual se halla nada menos que la astucia de los sacerdotes- el carácter moral se troca, pues, en su contrario: «La moral, ya no expresión de las condiciones de vida y crecimiento de un pueblo, ya no su instinto vital más hondo, sino convertida en algo abstracto, convertida en antítesis a la vida, -la moral como modo de volver por principio malas las cosas, como 'mal de ojo' para todas las cosas»" ${ }^{22}$.

A la pregunta fundamental que entonces se suscita de inmediato: "¿Quées moral judía, qué es moral cristiana?», sólo se puede dar, por tanto, una respuesta negativa. Moral es: «El azar, privado de su inocencia; la infelicidad, manchada con el concepto 'pecado'; el bienestar, considerado como peligro, como 'tentación'; el malestar fisiológico, envenenado con el gusano de la conciencia... ${ }^{23}$.

\footnotetext{
${ }^{20}$ AC $\$ 25$, KSA VI 193.

${ }^{21}$ AC $\$ 25$, KSA VI 194.

${ }^{22}$ Ibid.

${ }^{23}$ Ibid.
} 
Con la entrada en escena del 'hebreo Jesús' se hubiese podido modificar algo de todo esto. Pues, a ojos de Nietzsche, Jesús de Nazaret es un agitador contrario a la iglesia judía. Alguien que procuró oponerse a la casta de los escribas y que pronunció un «no a todo lo que era sacerdote y teólogo» ${ }^{24}$. Alguien que incitó a los «excluidos y 'pecadores'» para protestar contra el orden dominante y eso fue lo que lo llevó a la cruz.

Solamente por tal motivo ya es digna de mención, desde el punto de vista político, la actuación de Jesús de Nazaret. Pero la antítesis se agudiza considerablemente, según Nietzsche, cuando se contempla la alternativa ético-religiosa en la que vivió en realidad aquel hombre. Dicha alternativa contiene un ataque mucho más radical a la ortodoxia judía. De todas formas, Jesús fue mejor comprendido en su tiempo por los fariseos y los altos sacerdotes $y$, en todo caso, fueron sus discípulos quienes no entendieron nada. La singularidad de la 'práctica evangélica', el excepcional carácter existencial de la 'buena nueva' del amor realmente vivido no tuvo ningún sentido precisamente para quienes conformaron sobre esa base una enseñanza cristiana.

Prueba del difícil emplazamiento de las fuentes lo testimonia para Nietzsche el hecho de que los discípulos hayan intentado desarrollar a partir de la vida de Jesús una nueva religión. Pues, para Nietzsche, Jesús es «-una nueva forma de vida, no una nueva fe» ${ }^{25}$. Que se haya construido una nueva iglesia sobre la «infantilidad que se ha retirado a lo espiritual» de aquel hombre equilibrador de todas las contradicciones se le aparece a Nietzsche como la mayor forma de «ironía histórico-universal $»^{26}$ : «Ya la palabra 'cristianismo' es un malentendido-, en el fondo no ha habido más que un cristiano, y ése murió en la cruz» ${ }^{27}$.

Con esto, el juicio pronunciado contra los primeros cristianos resulta demoledor. Los evangelistas y, en particular, el apóstol Pablo -el «odio, hecho carne, hecho genio, del chandala, a Roma, al mundo» ${ }^{28}$, «el mayor de todos los apóstoles de la venganza ${ }^{29}$ - completan la victoria, consumada en la crucifixión, de la ortodoxia judía. Desde el momento en que inscriben todas las penalidades y cargas en la posición histórico-salvífica de los judíos, convierten el resentimiento en universal. Con el traslado de

\footnotetext{
${ }^{24}$ AC $\$ 27$, KSA VI 198

${ }^{25}$ AC $\$ 33$, KSA VI 206.

${ }^{26}$ AC $\$ 32$ y 36, KSA VI 203s. y 208.

${ }^{27}$ AC $\$ 39$, KSA VI 211.

${ }^{28}$ AC $\$ 58$, KSA VI 246

${ }^{29}$ AC $\$ 45$, KSA VI 223
} 
todas las esperanzas a una vida después de la vida, arrancan de su suelo todo ese sentido de la realidad. La consecuencia es una desvalorización de la realidad que abarca a la naturaleza en su conjunto: «En el mundo de representaciones del cristiano no aparece nada que roce siquiera la realidad: por el contrario, nosotros hemos reconocido en el odio instintivo $a$ toda realidad el elemento impulsor, el único elemento impulsor existente en la raíz del cristianismo ${ }^{30}$.

En última instancia, la disposición básica de la religión cristiana conduce a una orientación nihilista para con la propia vida: «Vivir de tal modo que ya no tenga sentido vivir, eso es lo que ahora se convierte en el 'sentido' de la vida ${ }^{31}$. «Nihilista y cristiano: estas palabras riman, y no sólo riman...»

Este síntoma histórico-universal de enfermedad consigue alzarse a su máxima expresión en la medida en que a la postre infecta todavía a un adversario principiante, es decir, al conocimiento científico. Propiamente, entre la ciencia y la fe se declara una oposición extrema-«se han terminado los sacerdotes y los dioses, si el hombre se vuelve científico»" «'Fe' significa no-querer-saber qué es verdadero» ${ }^{33}$. Por eso-según Nietzsche- se mostraban ya incompatibles el espíritu antiguo y el mensaje cristiano. Pero a lo largo de la dilatada historia de la sumisión de la cultura pagana por parte de la Iglesia también la ciencia llegó finalmente a ser domesticada. De ella se extrajo la libre conciencia del conocimiento. Perdió el coraje de la veracidad y el orgullo de la probidad; como 'ciencia moderna' se ejerce, desde ese momento, conforme a las exigencias del 'ideal ascético', más aún, no es sino la «forma más reciente y más noble del mismo» "34.

Los investigadores modernos pertenecen también desde hace tiempo, al igual que los sacerdotes, a la especie de los automortificadores. También ellos tienen por algo necesario el apartarse de sí mismos. Por eso ejercitan su ciencia como un medio para el 'aturdimiento de sí mismos'. Piensan y descubren en una pretendida inconsciencia porque, por encima por todo, temen una cosa, a saber "llegar a cobrar conciencia» ${ }^{35}$. Así se han convertido en 'agitadores del alma' que no perciben sino el hecho de que su esfuerzo por saber nada tiene que ver con ellos mismos. En este punto, resulta sumamente importante para la cabal comprensión del diagnóstico del nihilismo moderno

${ }^{30}$ AC $\$ 39$, KSA VI 212.

${ }^{31}$ AC $\$ 43$, KSA VI 217.

${ }^{32}$ AC $\$ 48$, KSA VI 227

${ }^{33}$ AC $\$ 52$, KSA VI 233

${ }^{34}$ GD III $\$ 23$, KSA V 396s.

${ }^{35}$ GD III $\$ 23$, KSA V 23 
la circunstancia de que Nietzsche se vincule a sí mismo al contexto criticado: «- también nosotros, los actuales hombres del conocimiento, nosotros los ateos y antimetafísicos, también nosotros extraemos nuestro fuego de aquella hoguera encendida por una fe milenaria, por aquella fe cristiana que fue también la fe de Platón, la creencia de que Dios es la verdad, de que la verdad es divina...."

A pesar de toda la enemistad originaria entre convicción y saber, entre fe y conocimiento, el ideal ascético ha conseguido seducir también a la ciencia. La psicología de la grandeza científica (y artística) esbozada por Nietzsche en el tercer tratado de La genealogía consigue hacer plausible esa dependencia. Cuán estrecha puede ser la vinculación se patentiza en el hecho de que ambas comparten de momento un mismo destino: la desvalorización del ideal ascético arrastra consigo necesariamente la pérdida de significado de la ciencia ${ }^{37}$. Esta es la fatalidad del hombre moderno, el cual, si desea tener un futuro, debe desembarazarse del ideal ascético -sin renunciar, empero, a la ciencia.

La fatalidad se hace consciente en líneas generales, según Nietzsche, en la consecuencia nihilista de la ciencia moderna. La superación de la vieja concepción teológica del mundo gracias a Copérnico no ha conducido precisamente, como hubiese sido de esperar, a la reprobación de la 'solución transmundana' al enigma de la existencia. El hombre ha renunciado a determinar nuevamente el valor de su existencia por medio de la confianza autoconsciente en su conquistado saber. No se hallaba lo bastante maduro para su conocimiento. Así que finalmente se ha dejado llevar hasta convertirse en un 'replegado' en su propia experiencia del mundo. La consecuencia no es simplemente una inconmensurable pérdida de valor de la voluntad de conocer, sino también la propia desvalorización del hombre, la cual tiene lugar en cualquier parte donde domine la ciencia -es decir, casi en todas partes. La victoria del nihilismo resulta así completa. "Desde Copérnico el hombre parece haber caído en un plano inclinado -rueda cada vez más rápido, alejándose del punto central- ¿Hacia dónde?, ¿ Hacia nada?, ¿Hacia el ,horadante sentimiento de la nada’... ¡Venga! Ese sería precisamente el camino recto - ¿Hacia el antiguo (ascético) ideal?» ${ }^{38}$.

Ya se mencionó antes el hecho de que Nietzsche se da por aludido en su propio diagnóstico. Usualmente, la crítica moderna de la cultura rechaza

${ }^{36}$ GD III $\$ 24$, KSA V 401.

${ }^{37}$ GM III $\$ 25$, KSA V 402.

${ }^{38}$ GM III $\$ 25$, KSA V 404. 
tan sólo el estilo de vida del otro, así como excluye su peculiar procedencia. Aquí ocurre de otra manera. Nietzsche incluye su propio pensamiento en el complejo epocal del nihilismo, que se manifiesta, junto con la ciencia moderna, en quiebra. Además, él sabe precisamente cuánto le debe -no solamente como hijo de sacerdote y filólogo, sino justamente como crítico radical- al dominio del sacerdote asceta y, en particular, al cristianismo paulino. La enseńanza cristiana fue, de modo ejemplar, aquella que en el curso de los siglos potenció de tal forma el valor de la interioridad que ésta pudo convertirse en criterio absoluto para las creencias individuales. Gracias a ello se convirtieron el conocimiento mutuo entre las personas, los juicios de experiencia y los razonamientos lógicos en criterios rectores para todo lo demás. Así pues, fue la cultura de la interioridad, perfeccionada por el cristianismo, la que favoreció la moderna ascensión de la ciencia. Para ello, también la fe fomentó, de modo indirecto, la crítica de la creencia, y eso llevó finalmente a que el espíritu de positividad, reforzado por las ciencias modernas, se pudiese oponer a las pruebas de la existencia de Dios y a los signos de la revelación. Por consiguiente, el temprano nihilismo judeocristiano sería la causa del 'nihilismo radical' del presente, en el cual aquél adquiere, por primera vez, una conciencia de sí mismo. "El nihilismo es un estado normal. Nibilismo: falta la meta, falta la respuesta al ¿por qué? ¿Qué significa nihilismo? - que los valores supremos se desvalorizan ${ }^{39}$.

Nihilismo significa, por tanto, que no hay respuesta a las grandes preguntas acerca del sentido. En eso reconocemos cuán estrechamente unido se encuentra el diagnóstico epocal con el pensamiento de Nietzsche; pues a fin de cuentas es él quien, como ningún otro en su siglo, formula las preguntas acerca del sentido. Y, de hecho, hay indicios de que su comprensión de la inevitabilidad del nihilismo le conmovió profundamente.

Un indicio de ello es la presentación de aquel conocimiento, en el que el diagnóstico del nihilismo encuentra su expresión más marcada: la tesis de la «muerte de Dios». Nadie como Nietzsche ha expresado de manera tan penetrante la transcendencia teórica y práctica del ateísmo moderno. Nadie ha formulado de manera tan contundente la historicidad del acontecimiento, por cuanto él proclamaba simplemente la muerte de un Dios en otro tiempo vivo; apenas nadie ha subrayado tan claramente su propia participación en tal proceso; y, seguro, no hay ningún otro que posea tanta lucidez para pronunciar por sí mismo esto como un conocimiento inevitablemente

${ }^{39}$ KSA XII 350: 9[35]. 
aceptado. Por eso lo pone en boca de Zaratustra ${ }^{40}$ e incluso lo expresa por primera vez como el desesperado grito de necesidad de un loco.

Todos los elementos mencionados se encuentran en el famoso aforismo 125 de La gaya ciencia, del cual solamente puede citarse aquí un fragmento. Quien quiera conocer algo acerca de Nietzsche, lea este aforismo palabra por palabra, preste atención a cada signo de puntuación y no deje perder ni el más mínimo significado de la puesta en escena:

«El hombre demente - No habéis oído de aquel hombre demente que en el luminoso medio día encendió una lámpara, corrió por el mercado e incansablemente gritó: ¡Busco a Dios!, ¡Busco a Dios!' -Puesto que allí estaban reunidos en ese momento muchos de aquellos los cuales no creía en Dios, provocó una enorme carcajada.

¿Se ha perdido? Dijo uno. ¿'Se ha despistado como un niño? ¿O permanece escondido? ¿Se atemoriza de nosotros? ¿Le ha ido demasiado mal? ¿Emigrado? -así gritaban y reían bulliciosos. El hombre insano saltó en medio de ellos y los traspasó con su mirada. ¿Dónde está Dios? gritó, ¡Yo quiero decíroslo! Nosotros lo hemos matado,- ¡vosotros y yo! ¡Todos nosotros somos sus asesinos! ¿Pero como lo habemos conseguido? ¿Quién nos dio la esponja para borrar el horizonte? ¿Qué pretendíamos cuando desencadenamos esta tierra de su sol? ¿Hacia donde se mueve ahora? Hacia donde nos movemos nosotros?» ${ }^{41}$

Éstas no son preguntas que Nietzsche ponga simplemente en boca de un orador cualquiera, algo así como un erudito. Estas son preguntas que él mismo tiene y que él mismo se plantea. Su análisis histórico le hace además estar seguro de que la pregunta, heredada única y exclusivamente por el hombre, por el lugar y la finalidad de la existencia humana tras la muerte de Dios, no permite una vuelta a las viejas respuestas. El nihilismo moderno supone un cambio de rumbo de la cultura europea, un tiempo de crisis, que adviene con necesidad histórica y que, si el hombre desea tener aún futuro, debe ser superado con las propias fuerzas. La 'transvaloración de los valores', consumada por la religión de los sacerdotes en el transcurso de los siglos, debe ser llevada hasta el final con todas sus consecuencias para posibilitar a partir de la lograda coyuntura nihilista una renovada -guiada contra aquel ascetismo arrebatado por el resentimiento- 'transvaloración de los valores'. Eso podría, pues, significar la 'gran convalecencia' de la cultura, la liberación de la 'moral de los señores' de su servidumbre y la aurora de la época del 'espíritu libre'. Los 'espíritus libres' podrán entonces reconocer

${ }^{40}$ Za Vorrede $\$ 2$, KSA IV 14.

${ }^{41} \mathrm{FW} \$ 125$, KSA III 480s. 
hasta qué grado son ellos creadores de nuevos valores y, de ese modo, sentirse capacitados para situar su 'sentido' en la historia ${ }^{42}$.

Para la realización de esta meta, deben ser destruidos en primer lugar, sin contemplaciones, los antiguos valores. Por eso se presenta Nietzsche como cumplimentador de toda critica de la religión habida hasta ahora y estima, tan resuelto como esperanzado, que él es el «primer nihilista integro de Europa que ha vivido el nihilismo ya en su propio acabamiento...»" ${ }^{43}$. Bajo esta convicción reivindica para sí un 'nihilismo activo' que, en plena consciencia de sus acrecentadas fuerzas intelectuales, critique los valores anteriores, $y$, sin embargo, no se conforme con que ya no exista ningún sentido ${ }^{44}$. Nietzsche coloca más bien todo el peso en la pregunta que previamente fue formulada de modo explícito por Schopenhauer y que afecta ahora a todos los hombres de una 'terrible manera' - ¿¿Posee pues la existencia un sentido?»-, a fin de poder comprenderla en su profundidad y responderla de una forma en la que nunca más sea purgada de vida y sentido ${ }^{45}$. En resumen: como el más consecuente nihilista quisiera Nietzsche superar el nihilismo y, cuanto menos, guiar hasta el umbral de una nueva 'transvaloración de los valores'.

$Y$ si en verdad fuera posible volver a conferir un sentido a la vida con esta 'transvaloración de los valores', de ello no podría sino desprenderse que el hombre no se renueva distanciándose de sí mismo, que el hombre no se niega, tal como fue el caso bajo el 'ideal ascético' de la 'voluntad débil', sino que al fin se pone de parte de sí mismo. Ha de comprenderse como 'espíritu libre' $-\mathrm{y}$, así, también, como sustancia finita plena de pretensiones- y no avergonzarse ni de su corporeidad ni de su origen terrenal. Sólo entonces, quizás, podrá conseguir rebasarse a sí mismo sin abandonar ni el mundo ni su historia. Y ése es precisamente el mensaje de Zaratustra: «iMirad, yo os enseño el superhombre! El superhombre es el sentido de la tierra. Diga vuestra voluntad llama: ¡Sea el superhombre el sentido de la tierra!» $Y$ añade a modo de aclaración: «iYo os conjuro, hermanos míos, permaneced fieles a la tierra y no creáis a quienes os hablan sobre esperanzas sobreterrenales! ¡Son envenenadores, lo sepan o no! ${ }^{46}$.

Entenderemos mejor el mensaje de Zaratustra si reconocemos contra quién va dirigido: a saber, de manera notoria y precisa, contra ningún otro

${ }^{42}$ KSA XII 243: 6[25].

${ }^{43}$ KSA XIII 190: 11[413].

${ }^{44}$ KSA XII 350s.: 9[35].

${ }^{45}$ Cf. FW $\$ 357$, KSA III 600.

${ }^{46} \mathrm{Za} I$ Vorrede, $\$ 3, \mathrm{KSA}$ IV 14. 
más que contra una visión apocalíptica del final de la historia. Zaratustra, el profeta retornado que introdujo entre los hombres hace más de dos mil años la diferenciación entre 'bueno' y 'malo', regresa ahora, renovado, a los hombres, para abolir dicha antítesis moral. Pero de ese modo se suprime el sentido de un juicio final y, por ello, el discurso sólo puede ser polémico. Los criterios absolutos, en función de los cuales todos podrían ser juzgados de modo homogéneo, ya no existen. Además, con la muerte de Dios desaparece también el poder insuperable del juez supremo. Y si no podemos confiar por más tiempo en la eficacia de un creador que nos procure un criterio y un fin, tampoco tiene ningún sentido seguir hablando de una finalidad o de una meta.

Por eso, Zaratustra halla en la doctrina del eterno retorno de lo mismo su "pensamiento más abismal», aquél que le libera de todo el 'hastío' que hubo de experimentar mientras todavía intentaba determinar la marcha de las cosas mediante una finalidad en la historia. De todo 'odio' hacia los hombres ya se libró durante sus diez años de soledad; así, en su retorno a los hombres puede ahora explicar que desciende hacia ellos con su 'amor' y la sobreabundancia de su sabiduría. Sí que desea establecer con su mensaje una finalidad en la tierra; pero dicha finalidad no debe orientarse hacia un lejano futuro, sino que debe brindarle ahora significado y fuerza para actuar.

El hombre no debe ocultar por más tiempo su cabeza dentro de la «arena de las cosas celestiales»" ${ }^{47}$, sino que debe aprender a decir 'Sí a esta vida, a las tareas existentes. Así, mientras se impone a sí mismo grandes tareas, mientras se da forma a sí mismo en la culminación de una obra y mientras crece en la autosuperación de sí mismo, aprende también a vivir sin un sentido absoluto de totalidad. A la postre, madura incluso en la comprensión del fracaso trágico de todo querer humano. Éste es el sentido de aquella promesa fatal del 'superhombre' y es, al mismo tiempo, la consecuencia humana de la doctrina de la 'voluntad de poder', que tan marcial resuena, pero que en realidad se ha ido forjando con profunda seriedad especulativa.

Todo eso se formula decididamente en contra de aquella visión de un final en la historia. El diagnóstico epocal y la crítica de la religión se sitúan ante todo en oposición natural a esa idea, creída con tanta devoción y tan enorme seriedad científica y política por los contemporáneos de Nietzsche, de un progreso en la historia. Por último, dado que esa exagerada esperanza en una conclusión positiva de nuestro futuro ha de ser desenmascarada, a las esperanzas en el progreso le sigue de inmediato la catástrofe. Quien cree en una finalidad en la historia, al final sólo puede vislumbrar el fracaso. De esa

${ }^{47} \mathrm{Za} \mathrm{I}$, «Von den Hinterweltlern», p. 37. 
forma, también el final, caso de que no lo fuera con anterioridad, se convierte necesariamente en apocalíptico. Y lo que Nietzsche quiere es ahorrarse y ahorrarnos a semejantes visionarios de la insanabilidad.

Espero que podamos reconocer también el sentido más profundo de su veredicto en contra del Apocalipsis de san Juan: dicho veredicto tendría que intensificar el repliegue histórico-filosófico en el presente, así como nuestra concentración en el instante vital de la realización del mundo y del sí mismo y, con ello, el desarrollo creativo de nuestra propia existencia. Por eso, bien se podría designar a Nietzsche como un filósofo anti-apocalíptico y a su $A s i$ habló Zaratustra como el libro anti-apocalíptico por excelencia.

La renuncia filosófica de Nietzsche a una desvalorización apocalíptica del propio presente es susceptible de corroboración filológica, a pesar de que, como hemos visto al principio, los pasajes hallados son más que escasos. Sin embargo, existen pruebas a favor de un consciente posicionamiento frontal de su obra en contra del Apocalipsis de san Juan en el Nuevo testamento. Los indicios se concentran en su Zaratustra, que es probable que Nietzsche haya concebido como una contrafigura de la del presunto autor del Apocalipsis. Quisiera concluir con algunos datos relativos a estos indicios ${ }^{48}$ :

Por La genealogía de la moral conocemos la opinión de Nietzsche de que la profecía de un cercano o lejano juicio al final de la historia nace de un lisiado espíritu de resentimiento. El Apocalipsis de san Juan está escrito, a su juicio, bajo el espíritu de Pablo, precisamente el «mayor apóstol de la venganza». Por medio suya querría la voluntad débil alcanzar la dominación definitiva. Si el hombre quisiera liberarse del lastre de la autonegación y del

\footnotetext{
${ }^{48}$ En este contexto me limito a algunos evidentes paralelismos de contenido entre ambos libros: en la nueva interpretación nietzscheana se ha llamado también la atención sobre estas similitudes formales. Así Lawrence Lampert (Nietzsche's Teaching. An interpretation of Thus Spoke Zarathustra, New Haven, 1986, pp. 240s.) ha intentado documentar que la división de Así habló Zarathustra repite la estructura de la Biblia. Los 66 libros bíblicos corresponden a los 66 capítulos (más bien, discursos) del Zaratustra. Se llega a esa cifra si se valora los siete párrafos del último capítulo de la tercera parte (Los siete sellos) como unidades independientes. Los respectivos 22 capítulos de las partes 1 y 2 del Zaratustra remiten, según Lampert, al capítulo 22 del Apocalipsis. La pretensión de Nietzsche de oponerse, en cuanto Anticristo, a la enseñanza platónica-cristiana con puntos de vista que resultan de la misma, estaría así cimentada. En una conferencia, todavía inédita, pronunciada en octubre de 1990 (en Villa Vigoni), Henning Ottmann examinó más de cerca la tesis de Lawrence Lamprecht y la encontró al menos tan plausible como la hipótesis, considerada por otros autores, acerca de la estructura sinfónica o matemática del libro. Cf. Janz, C. P., Friedrich Nietzsche, 2. Bd., München, pp. 211 ss.; Scheier, C.-A., Nietzsches Labyrinth. Das ursprüngliche Denken und Seele, Freiburg/München, 1985, pp. 167ss.
} 
constante alejamiento de sí mismo debería, entonces, admitir sus fortalezas y debilidades y vivir en el reconocimiento de sus (finitas) fuerzas. De eso es Zaratustra un ejemplo. Representa en todo la contrafigura de aquel 'apóstol de la venganza'. Por eso, tampoco debe extrañar cuando, en su caminar, resultan reconocible las inequívocas peregrinaciones de aquel 'Jesús, el hebreo'. Zaratustra predica en el espíritu del amor individual a los hombres y reúne 'hermanos' en torno a sí, como si fuesen sus discípulos.

En un apunte de sus fragmentos póstumos del verano 1881 anota Nietzsche que podría representarse el poder de expandirse de tal modo por encima de sí mismo y de la naturaleza circundante, que quizá hasta las propias águilas tendrían que alzar tímidamente la vista hacia él -como en la leyenda de san Juan ${ }^{49}$. Poco después, a este rasgo percibido en sí mismo le brinda figura literaria: Zaratustra. Como es sabido, Zaratustra reúne en torno suyo al águila y la serpiente; éstos alzan la vista hacia él y le hablan en confianza. En la figura de Zaratustra se dan cuando menos algunos elementos de aquella personalidad en la que Nietzsche, en sus años precoces, creía reconocer la continuación de la exaltación dionisíaca del mundo antiguo. Bajo la figura de Juan sólo reconoce, en verdad, al discípulo más amado de Jesús, al -como él lo llama- 'discípulo del amor' y, por consiguiente, no al autor del Apocalipsis; no obstante, también destacan en el camino de Zaratustra algunos momentos característicos del Apocalipsis de San Juan.

Éstos son, primeramente, el águila y la serpiente. Son los animales de Zaratustra, que se confían a él. Son ellos, si se lee con atención, los que le sugieren el pensamiento del eterno retorno. De esta manera resultan conciliados los dos animales simbólicos del Apocalipsis, hostiles entre sí, el águila celestial y la serpiente con forma de dragón, perteneciente a la depravada tierra. El ángel, que ruge en el Nuevo Testamento como un 'león' para anunciar el contenido del 'librito' en el que se halla escrito: «De aquí en adelante ya no habrá más tiempo" ${ }^{50}$, se mantiene en el discurso de Zaratustra como un león al que le pertenece el futuro (y, con ello, todo tiempo) si se transforma en 'niño', semejante a los ángeles, que, en ingenua devoción, sigue viviendo en el crear.

El león del Zaratustra se supera a sí mismo y así se reencuentra en la inocencia del nińo. De esta manera llegamos a uno de los temas centrales de la obra tardía de Nietzsche: la superación de sí mismo. Sin ella no se realiza verdaderamente ninguna empresa sobrehumana. No obstante, en el

${ }^{49}$ KSA IX 588: 12[72].

${ }^{50}$ Apocalipsis, 10, 6. 
Apocalipsis de san Juan esta superación es asimismo un motivo central de la imitatio Christi. Del mismo modo que los camaradas de Zaratustra deben 'superarse' a sí mismos si quieren seguir al maestro, así le ocurre también en el Apocalipsis a quien (en el seguimiento de Cristo) se 'supera's1.

Pero además de ello, tanto en uno como en otro caso a ambos les corresponden las mismas virtudes elementales. En la Biblia se pide a los creyentes 'fidelidad', 'veracidad' y 'justicia'. Precisamente éstos son los principales atributos apreciados por el 'espíritu libre' en sí mismo: a saber, la 'responsabilidad', como fidelidad ante las cosas y las personas, luego, la 'honradez' o 'veracidad' y, finalmente, la 'justicia' predicada por Zaratustra contra toda pusilanimidad y rendición de cuentas. Estas virtudes son las que provienen de los conocimientos que él anuncia tras su estancia en la 'isla de los bienaventurados'. El autor del Apocalipsis fue, como transmite la leyenda, poseído por el espíritu en la isla de 'Patmos' y allí recibió el mandato de explicar su visión a los creyentes. Únicamente debe anunciar el espanto que, con los símbolos del águila y la serpiente, ascendió hasta él desde el «pozo del abismo $»^{52}$, mientras que Zaratustra puede transmitir su "pensamiento más abismal», el pensamiento del eterno retorno.

Zaratustra querría hacer esto preferentemente riendo y cantando, después de que, en un primer momento, la náusea por la existencia le golpease, haciéndole caer sin conocimiento: cayó al suelo «como un muerto y permaneció largo tiempo como un muerto" ${ }^{53}$. Cuando el narrador del Apocalipsis es poseído por el espíritu y se le aparece el ángel del señor, cae «ante sus pies como muerto». Entonces el ángel se dirige a él: «iNo temas! Yo soy el primero y el último y el viviente. Yo estaba muerto, y mira, estoy vivo desde la eternidad hasta la eternidad y tengo las llaves de la muerte y del infierno" ${ }^{54}$. El águila y la serpiente le dicen al Zaratustra que despierta tras "tras siete días»:

"Oh Zaratustra, [...] hace ya sietes días así tendido, con pesadez en los ojos: ¿`No quieres por fin ponerte otra vez de pie?

Sal de tu caverna: el mundo te espera como un jardín. El viento juega con densos aromas que quieren venir hasta ti; y todos los arroyos quisieran seguirte en tu carrera.

Todas las cosas sienten anhelo de ti, porque has permanecido solo siete días, ¡Sal de tu caverna! ¡Todas las cosas quieren ser tus médicos!

${ }^{51}$ Apocalipsis, 3, 219.

${ }^{52}$ Apocalipsis, 9, 2.

${ }^{53} \mathrm{Za}$ III «Der Genesende», §2, KSA IV 271.

${ }^{54}$ Apocalipsis, 1, 17 y 18. 
¿Es que ha venido a ti un nuevo conocimiento, un conocimiento ácido, pesado? Como masa acedada yacías tú ahí, tu alma se hinchaba y rebosaba por todos sus bordes» ${ }^{55}$.

El conocimiento que asalta por sorpresa a Zaratustra en medio de su desvanecimiento y que en ese momento lo atrae con todas sus fuerzas de vuelta a la vida, será poco después parafraseado por sus animales: «Todo va, todo vuelve; eternamente rueda la rueda del ser. Todo muere, todo vuelve a florecer, eternamente corre el año del ser» ${ }^{56}$

Este es el pensamiento del eterno retorno. Sobreviene a Zaratustra en condiciones que son extremadamente parecidas a las del Apocalipsis de san Juan. Pero contiene un mensaje que se opone de forma diametral al del Apocalipsis, un mensaje alegre del principio al fin, en tanto que propiamente anuncia que todos los temores a un terrorífico fin de la historia son ilógicos. Ciertamente, no debe negarse que -allí donde quiera que miremos- todo pasa y todo muere. Sin embargo, toda muerte y todo fin conectan con un nuevo principio: «Todo vuelve», «todo florece de nuevo». Por consiguiente, no habrá ningún final definitivo ni tampoco ningún terrible juicio. La visión apocalíptica del fin del mundo es simplemente una invención del resentimiento, una venenosa astucia de los sacerdotes, que ha de crear en los fuertes mala conciencia y permitir a los débiles tenerse a sí mismos por adelantado como vencedores finales.

Sin embargo, éstos últimos permanecen bajo el maleficio del miedo. Pues para ellos rige el mensaje anunciado «con la gran voz» de los ángeles: «Teme a Dios y hazle honra, pues ha llegado la hora de su juicio» ${ }^{57}$. Por el contrario, Zaratustra, tras una primera desilusión que resulta de la consideración de que -si todo retorna- también lo vil, lo pequeño, lo penoso retornan, se reconcilia consigo mismo a través del mensaje anunciado por sus animales. La náusea ante la vida queda superada. Zaratustra es el convaleciente. De nuevo sonríe; al fin yace tranquilo, "como un durmiente», conversa «con su alma» y gana la fuerza necesaria para cantar, bailar y reír ${ }^{58}$. La risa es para Zaratustra la más segura y, como hemos visto aquí, la más real e inequívoca respuesta a la terrible visión del Apocalipsis.

traducción de Jesús Martín Cardoso

${ }^{55}$ Za III «Der Genesende», $\$ 2$, KSA IV 271s.
${ }^{56}$ Ibid.
${ }^{57}$ Apocalipsis, 14, 7.
${ }^{58}$ Za III «Der Genesende», $\$ 2$, KSA IV 275ss. 